\title{
Malignancies in HIV infected children at a tertiary cancer hospital in India
}

\author{
A Alahari Dhir*1, S Sawant ${ }^{1}$, G Bharia ${ }^{1}$ and S Banavali ${ }^{2}$
}

\author{
Address: ${ }^{1}$ Department of Medicine, Tata Memorial Hospital, Mumbai, India and ${ }^{2}$ Department of Pediatric Oncology, Tata Memorial Hospital, \\ Mumbai, India \\ * Corresponding author
}

from I I th International Conference on Malignancies in AIDS and Other Acquired Immunodeficiencies (ICMAOI): Basic, Epidemiologic, and Clinical Research

Bethesda, MD, USA. 6-7 October 2008

Published: 17 June 2009

Infectious Agents and Cancer 2009, 4(Suppl 2):P4 doi:10.1186/1750-9378-4-S2-P4

This abstract is available from: http://www.infectagentscancer.com/content/4/S2/P4

(C) 2009 Dhir et al; licensee BioMed Central Ltd.

\section{Aim}

To study the spectrum of malignancies in human immunodeficiency virus (HIV)-infected children and the clinical outcome of patients with these tumors.

\section{Methods}

An observational study was done of pediatric patients diagnosed with cancer and who were HIV-infected at the Tata Memorial Cancer Hospital, a tertiary referral cancer centre in Mumbai, India. The study period was 2001 to 2007. Data regarding demographic profiles, types of cancers, stage of cancer, treatment and outcome, immune status was analyzed. We used gender and age-specific proportions of pediatric cancer which were recorded in the Tata Hospital cancer registry in 2002 to estimate an expected number of pediatric cancers among HIV positive pediatric cancer patients during the 2001 to 2007. The proportional incidence ratio (PIR) was calculated.

\section{Results}

The hospital diagnosed 475 patients including adults and children with HIV and cancer between 2001 and 2007. Among them there were 11 children with HIV infection and cancer. All children except one were male. The median age was 7 years (range 4 to 12 years). All patients were HIV-infected by vertical transmission. Malignancy was the presenting illness in four (36.3\%) patients, after which the parents were diagnosed to be HIV-positive. All patients were $\mathrm{HBsAg}$ and $\mathrm{HCV}$ negative. $\mathrm{CD} 4$ counts were done in seven patients and the CD4 percentage was less than 14 percent in two patients. None of the children received HAART prior to being diagnosed with cancer. Four patients were started on concomitant chemotherapy and HAART. Nine patients $(81.8 \%)$ had Non-Hodgkin's lymphoma (NHL); there was one case $(9 \%)$ of B-ALL (acute lymphatic leukemia) and one case (9\%) of Hodgkin's disease. Among the NHL patients the histology included four cases of diffuse large B-cell lymphoma (DLBCL), two cases of plasmablastic and two cases of Burkitt's lymphoma, and one case of high grade lymphoma. One-third $(33.33 \%)$ of the patients had extra nodal disease and $66.66 \%$ of patients had advanced disease (stage III and IV). The PIR for NHL in male children was 9.71 (95\% CI 4.19-19.13). Out of the 11 patients, seven $(63.6 \%)$ received cancer directed treatment. Three patients received chemotherapy and radiotherapy and four patients received only chemotherapy.

One patient received prophylactic GCSF throughout chemotherapy and three received only with some cycles of CT after development of neutropenia. Adverse events included febrile neutropenia $(71.4 \%)$, candidiasis (42.8\%), diarrhea $(42.8 \%)$, otitis $(28.5 \%)$, CMV enterocolitis $(28.5 \%)$, varicella $(14.2 \%)$, pulmonary tuberculosis $(14.2 \%)$, mucositis $(71.4 \%)$, and hemorrhagic cystitis $(28.5 \%)$. Of the seven patients who received treatment, two $(28.5 \%)$ showed complete response, three $(42.8 \%)$ had progressive disease, one $(14.2 \%)$ was lost to follow up and one patient (14.2\%) is currently on therapy. Of the 11 patients, five expired: four patients died to disease 
progression and one patient died of infectious complication. The overall survival was 22.2 percent at 1 year.

\section{Conclusion}

NHL is the most common cancer among HIV-infected children and the PIR was significantly increased. Cancer may be the presenting AIDS-defining illness in HIVinfected children. Malignancies in children present at an advanced stage and have a poor prognosis. Significant immune suppression was not commonly seen. Association of HIV with cancers among children must be kept in mind by pediatricians especially in NHL. There should be a high index of suspicion for cancers among HIV-infected children.

Publish with Bio Med Central and every scientist can read your work free of charge

"BioMed Central will be the most significant development for disseminating the results of biomedical research in our lifetime. " Sir Paul Nurse, Cancer Research UK

Your research papers will be:

- available free of charge to the entire biomedical community

- peer reviewed and published immediately upon acceptance

- cited in PubMed and archived on PubMed Central

- yours - you keep the copyright

Submit your manuscript here:

http://www.biomedcentral.com/info/publishing_adv.asp 